\title{
Practical Use of Process Mapping to Guide Implementation of a Care Coordination Program for Rural Veterans
}

\author{
Marina S. McCreight, MPH ${ }^{1,2}$, Heather M. Gilmartin, $P h D, N P^{1,2,3}$,

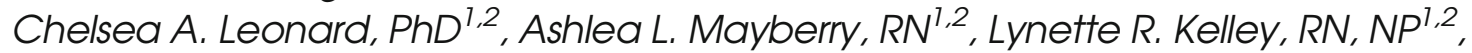 \\ Brandi K. Lippmann, MA ${ }^{1,2}$, Andrew S. Coy, BS ${ }^{1,2}$, Tiffany A. Radcliff, PhD4, \\ Murray J. Côté, $P H D^{4}$, and Robert E. Burke, $M D, M S^{5,6}$
}

'Seattle-Denver Center of Innovation for Veteran-Centered and Value-Driven Care, Denver, CO, USA; ${ }^{2}$ VA Eastern Colorado Health Care System, Denver, CO, USA; ${ }^{3}$ Colorado School of Public Health, University of Colorado, Aurora, CO, USA; ${ }^{4}$ Department of Health Policy and Management, School of Public Health, Texas A\&M University, College Station, TX, USA; ${ }^{5}$ Center for Health Equity Research and Promotion, Corporal Crescenz VA Medical Center, Philadelphia, PA, USA; ${ }^{\circ}$ Hospital Medicine Section, University of Pennsylvania Perelman School of Medicine, Philadelphia, PA, USA.

BACKGROUND: Transitions of care are high risk for vulnerable populations such as rural Veterans, and adequate care coordination can alleviate many risks. Single-center care coordination programs have shown promise in improving transitional care practices. However, best practices for implementing effective transitional care interventions are unknown, and a common pitfall is lack of understanding of the current process at different sites. The rural Transitions Nurse Program (TNP) is a Veterans Health Administration (VA) intervention that addresses the unique transitional care coordination needs of rural Veterans, and it is currently being implemented in five VA facilities.

OBJECTIVE: We sought to employ and study process mapping as a tool for assessing site context prior to implementation of TNP, a new care coordination program.

DESIGN AND PARTICIPANTS: Observational qualitative study guided by the Lean Six Sigma approach. Data were collected in January-March 2017 through interviews, direct observations, and group sessions with front-line staff, including VA providers, nurses, and administrative staff from five VA Medical Centers and nine rural PatientAligned Care Teams.

KEY RESULTS: We integrated key informant interviews, observational data, and group sessions to create ten process maps depicting the care coordination process prior to TNP implementation at each expansion site. These maps were used to adapt implementation through informing the unique role of the Transitions Nurse at each site and will be used in evaluating the program, which is essential to understanding the program's impact.

CONCLUSIONS: Process mapping can be a valuable and practical approach to accurately assess site processes before implementation of care coordination programs in complex systems. The process mapping activities were useful in engaging the local staff and simultaneously guided adaptations to the TNP intervention to meet local needs. Our approach-combining multiple data sources while adapting Lean Six Sigma principles into practical use-may be generalizable to other care coordination programs.

KEY WORDS: care coordination; process mapping; Veterans.

Published online May 16, 2019
J Gen Intern Med 34(Suppl1):S67-S74

DOI: $10.1007 / \mathrm{s} 11606-019-04968-\mathrm{x}$

(c) Society of General Internal Medicine (This is a U.S. government work and not under copyright protection in the U.S.; foreign copyright protection may apply) 2019

\section{INTRODUCTION}

Process mapping is a tool used in Lean Six Sigma process improvement methodology, which originated in the manufacturing industry ${ }^{1,2}$ and has increasingly been applied in service organizations, such as health care, to improve existing processes. $^{3-8}$ Process mapping involves observing steps, identifying roles involved, and specifying process inputs and outputs. ${ }^{8}$ To be most useful, it must include perspectives of staff on the "frontline" who currently perform the process in question. Data gathered from direct observations and discussions are then used to create a diagram or flowchart to depict this process. ${ }^{8}$ Although process mapping is frequently applied within health systems to improve processes, ${ }^{3,5,7}$ its potential as a pre-implementation and evaluation tool for evidence-based interventions has not been explored.

The Transitions Nurse Program (TNP) is a novel nurse-led care coordination program in the Veterans Health Administration (VA) built on the recognition that discharges home for rural Veterans hospitalized at tertiary VA sites are particularly high risk and poorly coordinated. ${ }^{9,10}$ A Transitions Nurse (TN) facilitates care coordination and communication activities with rural Veterans and their primary care clinics around the time of hospital discharge in addition to working with the Veteran directly preand post-discharge to ensure his or her care coordination needs are met. Based on promising pilot data at one site, TNP was funded to expand to five additional VA sites beginning in 2016.

Since care coordination requires multiple inputs and outputs, personnel involved, and care settings, rigorous process mapping may be useful for understanding the current state and providing key insights into how processes change as the result of care coordination interventions. In addition, few tools have been described that have demonstrated utility in accurately 
assessing context prior to implementation of a new process (a central tenet of implementation science ${ }^{11-13}$ ), particularly in care coordination. We thus sought to use the opportunity to expand TNP to employ and study process mapping as a tool to assess each expansion site's current processes and to use these findings to adapt implementation of TNP at each site. The purpose of this paper is to describe the novel application of process mapping in implementation of the clinical intervention as well as our findings and lessons learned.

\section{METHODS}

Using qualitative methods and Lean Six Sigma (LSS) processing mapping approach, ${ }^{8}$ we assessed the current, or pre-implementation, state of transitional care coordination for rural Veterans at five VA Medical Center (VAMC) and associated VA Patient-Aligned Care Team (PACT) sites two months prior to TNP implementation. We adapted the LSS process mapping method to collect process data using an iterative, multi-step approach during a larger pre-implementation assessment. ${ }^{10}$ During the first step, we designed preliminary process maps using data collected from semi-structured interviews with front-line staff, providers, and other stakeholders directly involved in the process. The interview guide was based on the Ideal Transitions of Care framework (ITC), which proposes ten domains needed for high-quality transitions of care, that has been used in other contexts to assess care transitions practices, ${ }^{14-18}$ and it is attached as Appendix Table 3. We interviewed at least three participants in various roles to allow for diversity of data to inform preliminary maps. ${ }^{19,20}$ We used purposive sampling to identify potential participants in specific roles and a snowball sampling to identify additional participants. The interviews were conducted over the phone, lasting approximately 30 to $90 \mathrm{~min}$; they were recorded and transcribed verbatim. Iterative team-based conventional content analysis techniques were used to analyze the interview data. The identified process steps were assimilated into a preliminary process map using the Microsoft Visio flowchart and diagramming software. ${ }^{21}$

The second step took place during pre-implementation site visits to observe direct workflow. This step served to "fine-tune" the process maps and identify any discordance between stakeholder interviews and current practice. At a VAMC, project teams observed various multidisciplinary teams in their everyday work routine around discharging rural Veterans. To account for variations, participants were asked to describe the most likely scenario. The observations usually took place in the first part of the day, during clinical and multidisciplinary rounds. We also timed the processes when possible or solicited the best assessment of how much time each step required from participants. Next, we conducted a one-hour group meeting with various frontline providers and staff at each expansion VAMC, facilitated by the experienced qualitative analysts (CL, EL, MM). During these group meetings, we presented our preliminary maps and solicited feedback about roles involved, timing, and sequence of process steps. Additionally, we explored their opinions about the elements of the current process that worked well or required improvement, as well as to how best include the TN role in the current local care coordination process.

Similarly, we visited a rural PACT site associated with each expansion VAMC to conduct observations and present our preliminary process maps to a multidisciplinary group of clinicians at the site. We selected two PACT sites with the highest referral rates for each expansion VAMC; however, due to low referral numbers and greater distance, we planned only one PACT site visit for one of the expansion VAMCs. During the site visit, we asked opinions on the state of the current process, as well as perspectives about the TN role and responsibilities. At the end of site observations, the project team verbally debriefed the visit, compared observational notes, and reflected on site feedback on the process maps. Once back from the site visit, the project team modified the process maps into a final form using the Microsoft Visio application.

The third step involved presenting the finalized maps to the expansion site teams (i.e., the site TN and site champion) to gather insights, brainstorm adaptations for the TN role, and inform individualized TNP implementation process.

Our goal was to capture diverse perspectives from front-line participants in the process. We sought to ensure our maps were as accurate as possible through sharing these maps with key stakeholders at each site, obtaining information about key processes through more than one qualitative tool, and conducting site visits with at least two TNP team members who could triangulate their observations. The scope of our observational process began when a rural Veteran was being prepared for discharge from a tertiary VAMC and ended with a follow-up with their PACT. Additionally, we looked for specific tasks in the process based on the ITC framework, ${ }^{14}$ and these included VAMC clinical teams notifying and coordinating follow-up with rural PACT, educating veterans about follow-up care, and following up with the Veteran postdischarge to specifically assess components the TNP program included in its pilot intervention. A multidisciplinary team consisting of two clinical coordinators (LK, AM, both registered nurses), four experienced qualitative analysts (one with Lean Six Sigma Yellow Belt certification (MM), CL, EL, AL), and one project manager (BL) conducted the data collection and analysis. These efforts were not considered human subject research per VA Office of Regulatory Oversight policy 1058.05 and were designated as quality improvement by the VA Office of Rural Health. 


\section{RESULTS}

We collected data in January-March 2017 from five VAMCs and nine rural PACT sites. We conducted 42 key informant interviews prior to the site visits with VA clinicians (7 physicians, 17 registered nurses, and 3 social workers) as well as administrative staff (15) who were knowledgeable about transitional care coordination in their facilities. These data were used to construct preliminary process maps. Then we conducted 41 process observations (over $23 \mathrm{~h}$ in duration). Finally, we hosted 14 group meetings with 140 front-line providers and staff, with meeting attendance ranging from three to 26 participants, as presented in Table 1. Participants included registered nurses (36), physicians (21), administrative staff (19), licensed practical nurses (8), social workers (8), and pharmacists (8). For additional 40 staff members, only aggregate personnel data were collected (Table 1).

We integrated key informant interviews, observational data, and group sessions to create ten process maps, one for each expansion VAMC and corresponding PACT sites. The final maps portrayed the transitional care coordination process prior to the TNP implementation from the perspectives of both VAMC inpatient and rural PACT outpatient teams. Overall, VAMC process maps provided a detailed visual depiction of the multidisciplinary roles involved and the complexities near the time of the discharge. We present here one VAMC map example on Figure 1. It displayed that multidisciplinary teams got involved early in the discharge planning and care coordination, while inpatient clinical teams tended to drive the process progression and timeline. Additionally, medication reconciliation, clinical discharge order verification, and patient education were important process steps and involved collaboration from all the multidisciplinary team members. PACT process maps (an example is shown on Fig. 2) exhibited that across all sites the process depended largely on the patient discharge notification, which triggered the PACT care coordination protocol.

We also learned that the transitional care coordination process varied across the sites in ways that were important to implementation of a new intervention. Overall, most processes were aligned with domains in the ITC framework
(Table 2), with VAMC clinical teams carrying out most of pre-discharge tasks, and PACT teams focusing on postdischarge processes. One notable observation was that effective communication and organization of information were limited to the intra-facility teams (clinical teams within the same facility), while communication between interfacility teams was challenging with limited information transferred between sites, if at all.

We observed that facilities varied in which clinical roles were involved in the patient discharge and care coordination processes, and the specific tasks performed by various staff. For example, at one site a pharmacist rounded with the medical team and was available to provide medication reconciliation during the discharge patient education. At another site, patients were instructed to stop by the pharmacy office on the way out of the hospital to pick up their medications and receive medication education. Another example was a role of "discharge expeditor" at one site who ensured that each Veteran was prepared to leave the hospital with everything they needed at the time of discharge. Yet at another site we observed an absence of case managers or similar roles during the discharge, leaving Veterans vulnerable to gaps in care coordination and adverse events. Additionally, we observed differences in patient education approaches at discharge. For example, one site tasked a physician with in-depth discharge patient education, while another assigned this responsibility to inpatient nurses.

Another key difference we noted was how multidisciplinary team rounds took place. At one site, these rounds were organized as team huddles, with all the multidisciplinary team members present and discussing the discharge coordination in real time. At others, the rounds included one representative from each multidisciplinary team who would deliver the discharge information to a larger multidisciplinary team afterwards. At one site, a multidisciplinary team walked between wards and floors to meet with separate clinical teams at assigned time slots and discuss discharge planning, while at others all team members met at a designated time and place.

Table 1 Description of the Participants in the Group Process Mapping Sessions

\begin{tabular}{|c|c|c|c|c|c|c|}
\hline \multirow[t]{2}{*}{ VAMC } & \multicolumn{2}{|c|}{$\begin{array}{l}\text { Number of interviews } \\
\text { conducted }\end{array}$} & \multirow[t]{2}{*}{ Number of PACTs Visited } & \multirow[t]{2}{*}{$\begin{array}{l}\text { Number of observations } \\
\text { conducted }\end{array}$} & \multicolumn{2}{|c|}{$\begin{array}{l}\text { Number of process } \\
\text { mapping activity } \\
\text { participants }\end{array}$} \\
\hline & VAMC & PACT & & & VAMC & PACT \\
\hline $\begin{array}{l}A \\
B \\
C \\
D \\
E\end{array}$ & $\begin{array}{l}3 \\
4 \\
6 \\
3 \\
5\end{array}$ & $\begin{array}{l}4 \\
0^{1} \\
4 \\
4 \\
6\end{array}$ & $\begin{array}{l}2 \\
1 \\
2 \\
2 \\
2\end{array}$ & $\begin{array}{l}11 \\
10 \\
5 \\
9 \\
6\end{array}$ & $\begin{array}{l}14^{2} \\
26 \\
13 \\
15 \\
9\end{array}$ & $\begin{array}{l}26^{2} \\
3 \\
10 \\
18 \\
6\end{array}$ \\
\hline
\end{tabular}

VAMC VA Medical Center, PACT patient-aligned care team, or primary care team in the VA

${ }^{I}$ No eligible interview participants were available

${ }^{2}$ Aggregate participant data were collected. Specific participants' role data were not available 


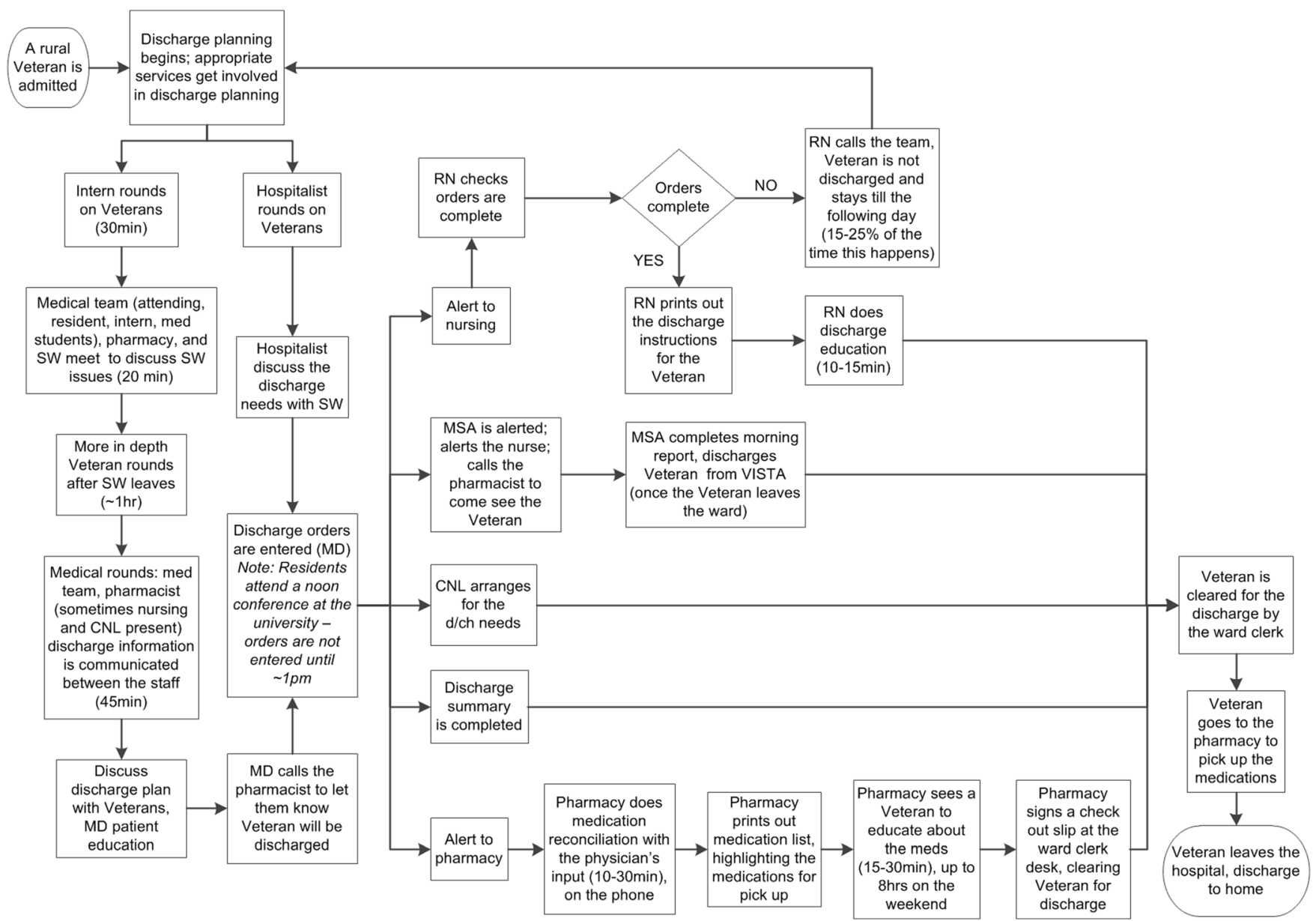

Figure 1 VAMC current transitional care coordination process map example. The process map was designed using Microsoft Visio 2010. This is an example of a process map that was presented to the Rural Transitions Nurse Program (TNP) implementing teams at each of the five VA Medical Centers to inform the adaptations to the program fit and implementation. CNL, clinical nurse lead; MD, medical doctor; MSA, medical support assistant; RN, registered nurse; SW, social worker; VISTA, VA electronic medical record system.

VAMC clinical teams also varied in how they notified the rural PACT about patient discharge and follow-up care needs. Some PACT sites shared local instances of VA's electronic medical record (EMR), which allowed notification of PACT and VAMC providers of each other's clinical notes. The process was more challenging when the sites were not part of the same local EMR "instance," requiring VAMC and PACT staff to look through "remote data" to find information and disabling easy EMR notifications. Notifications of a discharged Veteran varied from receiving an automated notice from a data portal, an EMR alert, or even a phone call from the Veteran or their caregivers. PACT case managers also stated that there was insufficient information provided on these alerts to coordinate care. Therefore, they often needed to conduct additional time-consuming investigations in the EMR to learn the details of the hospitalization and follow-up care recommendations.

We also observed multiple similarities. At each site, the overall discharge planning process began upon Veteran admission, with multidisciplinary teams involved in the process from the beginning. Within all sites, multidisciplinary teams communicated either by phone, instant messaging, or EMR alerts and checked in with each other on a regular basis during the Veteran inpatient stay. They also considered each other's recommendations when making decisions regarding discharge timeline and follow-up care. Although we did not interview Veterans directly on the process for this aspect of our pre-implementation site assessment, we were present with Veterans receiving discharge counseling. As an example, we observed the discharge process to be fast moving and seemed chaotic and overwhelming to the Veterans. We observed Veterans frequently had questions even after a physician or nurse had completed discharge counseling.

In presenting these maps to site champions, we had the opportunity to evaluate where care coordination processes seemed to be functioning well and poorly, and how this might affect TNP adaptation and the TN role. For example, we learned that two sites had a discharge coordinator 


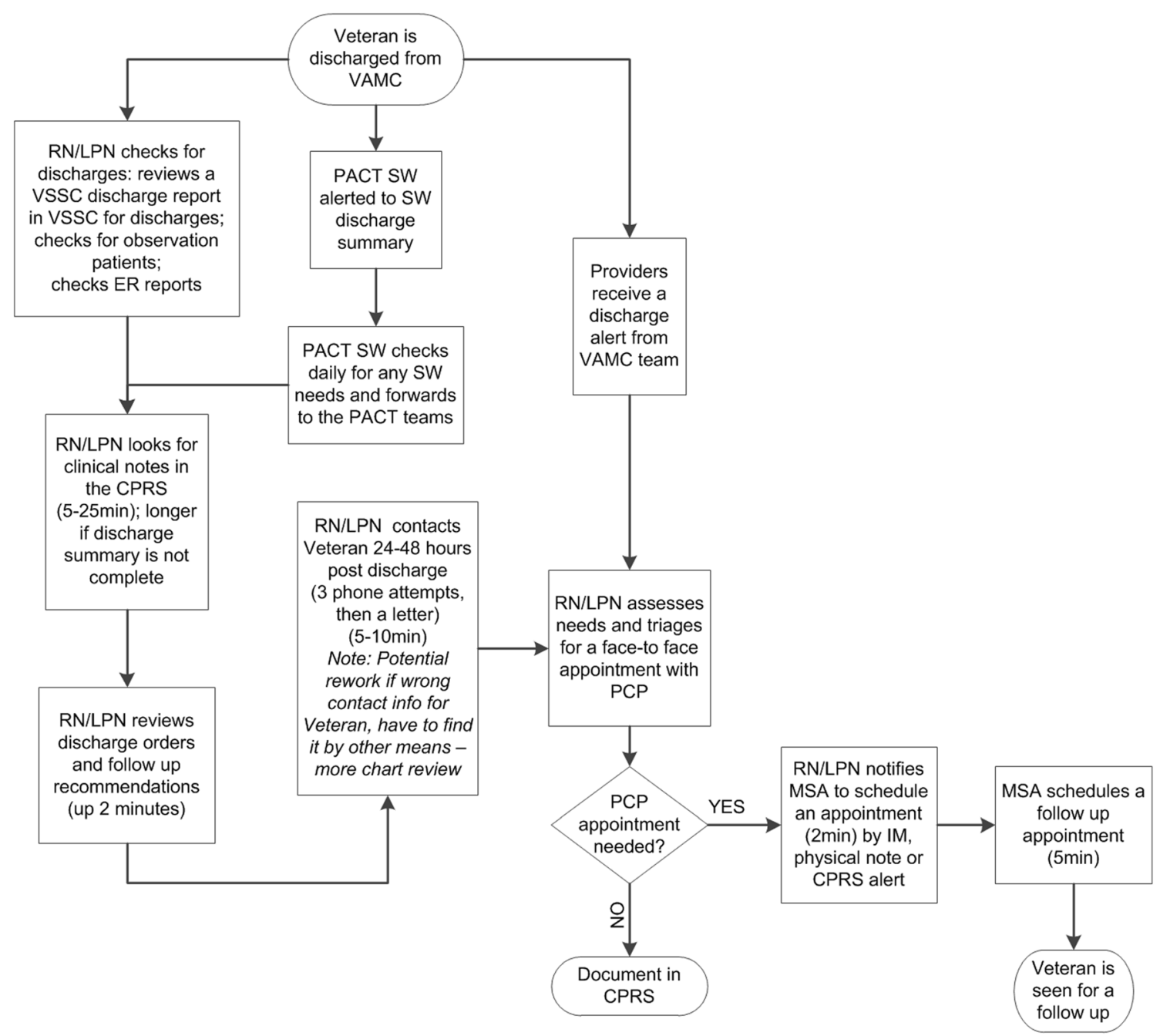

Figure 2 PACT current transitional care coordination process map example. The process map was designed using Microsoft Visio 2010. This is an example of a process map that was presented to the Rural Transitions Nurse Program (TNP) implementing teams at each of the five VA Medical Centers to inform the adaptations to the program fit and implementation. CNL, clinical nurse lead; CPRS, computerized patient record system, or electronic medical records in the VA; ER, emergency room; IM, instant message; LPN, licensed practical nurse; MD, medical doctor; MSA, medical support assistant; PACT, patient-aligned care team, or primary care team in the VA; PCP, primary care provider; RN, registered nurse; SW, social worker; VAMC, VA Medical Center; VISTA, VA electronic medical record system; VCCS, Veterans Health Administration Support Service Center.

role that possibly overlapped with a TN role. However, we learned they did not follow up with a Veteran after discharge, and were often not aware of what happened once a Veteran left a VAMC. In these sites, the TNs could complement these roles by facilitating communications with PACT, conducting additional patient follow-up, and relaying clinical information back to VAMC teams. We found that multidisciplinary rounds were likely a good method for TNs to identify rural Veterans they could enroll in the program at every site. We also recognized several care coordination process gaps could be addressed through adaptations to the TN role. For example, if the pharmacy was short-staffed or otherwise not readily available for individualized medication reconciliation with patients, the TNs could conduct medication reconciliation during the discharge process. We also emphasized the importance of facilitating timely communications between discharging VAMC and receiving PACT teams to ensure effective transitional care coordination.

Overall, each expansion site TN would need to be aware of all the local roles and responsibilities involved in this multi-step discharge process to effectively deliver the TNP program components.

\section{DISCUSSION}

We used the process mapping tool to identify the current care coordination process at each expansion site, which helped inform the role and fit of the TN with the existing clinical roles and procedures, as well as customize the implementation process. The final process maps included 


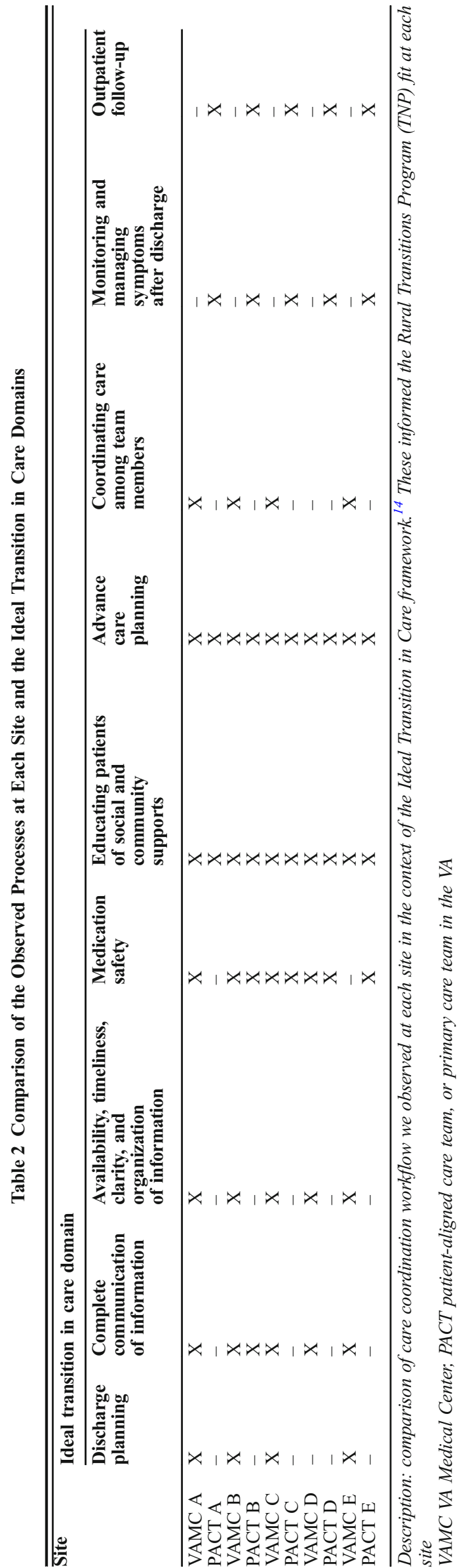

the process perspectives of both VAMC inpatient clinical teams and PACT primary care teams and highlighted the unique roles and practices at each facility.

Current applications of LSS in the health care industry focus on optimizing existing clinical and administrative processes by identifying and eliminating process inefficiencies and optimizing work flow. ${ }^{4,6,22,23}$ We modified and applied the LSS approach, and specifically, the process mapping tool, for a different purpose - to introduce a new role into an existing process while optimizing program uptake and ensuring minimal workflow disruptions. Moreover, we modified the LSS method to iteratively add new information to the process maps as we engaged new stakeholders until we seemingly achieved some level of saturation - until no new information appeared. Next, we plan to continue using process mapping in the ongoing TNP implementation and evaluation to track how the intervention process and, potentially, the $\mathrm{TN}$ role are modified at each site. We will do this through capture of the roles involved in the care coordination process and accurate measure of their time involvement. These efforts will also inform the economic analysis of the program, as changes in both time commitments and other costs can be estimated from the collected process data.

Although it was helpful to interview key informants before the site visits, we learned that interview participants did not always provide the level of details needed to create an accurate process map. The preliminary process maps required further refinement through direct observation, since stakeholder interviews may have had desirability bias (telling the interviewer what the interviewee thinks they want to hear) or may not have reflected site practice on the ground. Moreover, direct observations were helpful to identify redundancies and to understand which parts of the process were "owned" by different stakeholders. Group mapping sessions were useful to validate what we heard in the key informant interviews and observed on site visits. Therefore, although intensive, our multi-step approach to process mapping was valuable to understand the current process and recognize where to integrate the $\mathrm{TN}$ role. In addition, process mapping was demonstrated to be a practical tool as it was easy to learn and it required little technical experience beyond some fluency with the context of the map (e.g., identifying the start and end of the process) and software to facilitate the construction of the process maps.

We had several challenges. One of the greatest challenges in collecting data for this project was planning a group session with multidisciplinary team members; it was problematic to get them all in the same room at the same time for more than one hour due to their clinical schedules and other time demands, which was the most common reason for not participating. We began reaching out to potential participants at least two months prior to the site visit and worked closely with a local site contact to plan a schedule that accommodated most 
participants. While on site, we invited participants from our observations to attend the group meeting. We learned here that while we needed to plan early, we still needed to be agile and adaptable in our approach to include the right stakeholders at the right time to improve data collection.

Another challenge to data collection was engaging the participants in the process discussion. A facilitator with active listening and acute observational skills, able to engage all levels of organizational hierarchy and build a safe place for sharing of process steps and perspectives, was needed to keep the discussion moving forward.

Additionally, direct observations were challenging as staff with no vested interest in the TNP or data collection process were not always receptive to being observed. At one site, we learned we were mistaken for observers from an accreditation body, and we were not able to observe as planned. We prepared for future site visits by notifying an immediate supervisor prior to the observations. During the site visits, we clearly communicated to staff who we were and our intentions for observations.

Additional challenges were situations when staff wanted to describe the best-case scenario, minimize variations (which may be perceived as defects in the process), and often describe how the process should be versus how the process is currently being conducted. Observers must recognize these challenges and keep directing their probes back to the current state. Observing various roles involved also helped provide a more complete depiction of the process.

Given the variations in processes we found, our process maps are unlikely to be generalizable, but our approach may be useful in a variety of settings to assess current processes in complex systems. Additionally, process mapping is a useful tool to visualize any process and is readily applicable to health care service delivery projects.

Process mapping is a valuable approach to identify the current transitional care coordination in complex systems. It can be used before and during program implementation and provides insights into processes, role variations, and process inefficiencies, thus informing and customizing the design and implementation of clinical quality improvement interventions. This project demonstrated that it is important to understand the existing local processes in clinical settings when planning implementation of new programs. Moreover, methods to assess local processes need to be sufficiently flexible to engage the right stakeholders at the right time, as well as appropriately iterative to allow new information to be added as new stakeholders are engaged - all of which was demonstrated in the application of process mapping.

\section{Acknowledgements:}

We would like to thank the VA Office Rural Health and Office of Nursing Services for their support of the TNP. We also thank the staff who participated in the interviews and group meetings as part of the TNP.
Funding Acknowledgements: This work was supported by the VA Office of Rural Health, which funded the Transitions Nurse Program (N19-FY14Q3-SO-P01240) in coordination with the VA Office of Nursing Services. The sponsor had no role in the design, conduct, analysis, interpretation or presentation of the study. Dr. Burke was supported by a VA Career Development Award.

Corresponding Author: Marina S. McCreight, MPH; VA Eastern Colorado Health Care System, Denver, CO, USA (e-mail: Marina. McCreight@va.gov).

\section{Compliance with Ethical Standards:}

Conflict of Interest: The authors declare that they do not have a conflict of interest.

Disclaimer: The contents of this manuscript do not represent the views of the Department of Veterans Affairs or the United States Government.

\section{APPENDIX}

\section{Table 3 Current Process Interview Questions}

Excerpt from the Key Informant Interview Guide:

- Could you please walk me though what happens when a rural Veteran is discharged, starting with the discharge decision, all the way to the first PCP follow-up?

$\circ$ What is your role in this process?

o Can you tell me how...?

- What do you mean by...?

$\circ$ Is this common transition?

$\circ$ Additional probes to help with process mapping, if participant is highly involved in discharge process (i.e. RN, discharge planner, social work, etc)

- How does discharge process take place?

-When does the discharge planning begins?

- Who (what staff roles) is involved in getting the Veteran ready for discharge?

- Who specifically performs discharge patient counseling and medication reconciliation and at what point in the process?

- Do you contact PACT teams about a discharged Veteran? How do you notify PACT that a Veteran is being discharged from VAMC?

- Do you send any information to the PACT teams?

- If yes, what kind of information and how do you send this information?

- Do you schedules follow-up appointments for the Veteran as they are being discharged from your VAMC?

Process Mapping Interview Guide:

During the interview:

- Maintain the process perspective: What, where, how, roles involved in the process

- Define the scope of the process and identify any additional steps in the process

- Identify any additional decision points, loops, reworks, bottlenecks

- Identify process time at each step and between steps: best case scenario, worst case scenario, average time

- Identify if any movement takes place between the steps, such as walking to a different floor, carrying forms to a different office, etc.

- Define external and internal customers

- Identify any obstacles/barriers/wastes in the process

- Identify any variation in the process

-What are some replicable best practices/ facilitators to the current process?

1. To start, can you tell me your title and role here at (name of facility)?

a. How long have you been in this role?

b. What is your role in the transition process?

2. Could you please walk me though the process of admitting, caring for, and discharging a rural Veteran. We would like to know step-bystep process and what takes place at each step, staff involved and the time it takes to complete the step. For the purpose of this discussion we will end the process when the PACT team is notified about the discharged Veteran.

3. Continue "walking" through the process using the probes above. 
Table 4 Consolidated Criteria for Reporting Qualitative Research (COREQ) Table

\begin{tabular}{|c|c|}
\hline Item & $\begin{array}{l}\text { Location in } \\
\text { Manuscript }\end{array}$ \\
\hline \multicolumn{2}{|l|}{ Domain 1: Research team and reflexivity } \\
\hline \multicolumn{2}{|l|}{ Personal Characteristics } \\
\hline Which author (s) conducted the focus groups? & Pg. 7 \\
\hline What were the researcher's credentials? & Pg. 1 \\
\hline $\begin{array}{l}\text { What was their occupation at the time of the } \\
\text { study? }\end{array}$ & Pg. 8 \\
\hline Was the researcher male or female? & Pg. 1 \\
\hline \multirow{2}{*}{\multicolumn{2}{|c|}{ have? }} \\
\hline & \\
\hline \multicolumn{2}{|l|}{ Relationship with Participants } \\
\hline $\begin{array}{l}\text { Was a relationship established prior to study } \\
\text { commencement? }\end{array}$ & Pg. 15,16 \\
\hline $\begin{array}{l}\text { What did the participants know about the } \\
\text { researcher }(\mathrm{s}) \text { ? }\end{array}$ & Pg. 15,16 \\
\hline $\begin{array}{l}\text { What characteristics were reported about the } \\
\text { facilitator(s)? }\end{array}$ & Pg. 15 \\
\hline \multicolumn{2}{|l|}{ Domain 2: Study Design } \\
\hline \multicolumn{2}{|l|}{ Theoretical Framework } \\
\hline $\begin{array}{l}\text { What methodological orientation was stated to } \\
\text { underpin the study? }\end{array}$ & Pg. 6 \\
\hline \multicolumn{2}{|l|}{ Participant Selection } \\
\hline How were participants selected? (sampling) & Pg. 6 \\
\hline $\begin{array}{l}\text { How were participants approached? (method of } \\
\text { approach) }\end{array}$ & Pg. $6,7,9,15$ \\
\hline $\begin{array}{l}\text { How many participants were in the study (sample } \\
\text { size) }\end{array}$ & Pg. 9; Table 1 \\
\hline $\begin{array}{l}\text { How many people refused to participate or } \\
\text { dropped out? Reasons? (Non-participation) }\end{array}$ & Pg. 15,16 \\
\hline \multicolumn{2}{|l|}{ Setting } \\
\hline Where was the data collected? & Pg. 6,7 \\
\hline 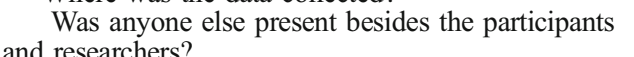 & Pg. 9 \\
\hline $\begin{array}{l}\text { What are the important characteristics of the } \\
\text { sample? }\end{array}$ & Pg. 9 \\
\hline \multicolumn{2}{|l|}{ Data collection } \\
\hline $\begin{array}{l}\text { Were questions, prompts, guides provided by the } \\
\text { authors? Pilot tested? }\end{array}$ & Pg. 27-29 \\
\hline $\begin{array}{l}\text { Were repeat interviews carried out? If yes, how } \\
\text { many? }\end{array}$ & N/A \\
\hline $\begin{array}{l}\text { Did the research use audio or visual recording to } \\
\text { collect the data? }\end{array}$ & Pg. 7 \\
\hline $\begin{array}{l}\text { Were field notes made during and/or after the focus } \\
\text { groups? }\end{array}$ & Pg. 6-9 \\
\hline What was the duration of the focus groups? & Pg. 7 \\
\hline Was data saturation discussed? & Pg. 6 \\
\hline $\begin{array}{l}\text { Were transcripts returned to participants for } \\
\text { comment and/or correction? }\end{array}$ & N/A \\
\hline \multicolumn{2}{|l|}{ Domain 3: Analysis and Findings } \\
\hline \multicolumn{2}{|l|}{ Data Analysis } \\
\hline How many data coders coded the data? & N/A \\
\hline $\begin{array}{l}\text { Did authors provide a description of the coding } \\
\text { tree? }\end{array}$ & N/A \\
\hline $\begin{array}{l}\text { Were themes identified in advance or derived from } \\
\text { the data? }\end{array}$ & Pg. 7, 9-13 \\
\hline $\begin{array}{l}\text { What software, if applicable, was used to manage } \\
\text { the data? }\end{array}$ & $\begin{array}{l}\text { Pg. } \\
7,8,10,25,26\end{array}$ \\
\hline Did participants provide feedback on the findings? & Pg. 7,8 \\
\hline Reporting & \\
\hline $\begin{array}{l}\text { Were participant quotations presented to illustrate } \\
\text { the themes/findings? Was each quotation identified? }\end{array}$ & $\mathrm{N} / \mathrm{A}$ \\
\hline $\begin{array}{l}\text { Was there consistency between the data presented } \\
\text { and the findings? }\end{array}$ & Yes \\
\hline $\begin{array}{l}\text { Were major themes clearly presented in the } \\
\text { findings? }\end{array}$ & Yes \\
\hline $\begin{array}{l}\text { Is there a description of diverse cases or discussion } \\
\text { of minor themes? }\end{array}$ & Yes \\
\hline
\end{tabular}

\section{REFERENCES}

1. Johnson JE, Smith AL, Mastro KA. From Toyota to the bedside nurses can lead the lean way in health care reform. Nurs Admin Q. 2012;36(3):234-42.

2. Kim CS, Spahlinger DA, Kin JM, Billi JE. Lean health care: what can hospitals learn from a world-class automaker? J Hosp Med. 2006;1:191-9.

3. Cima RR, Brown MJ, Hebl JR, et al. Use of Lean and Six Sigma methodology to improve operating room efficiency in a high-volume tertiary-care academic medical center. J Am Coll Surg. 2011;213:83-94.

4. Crema M, Verbano C. Lean management to support choosing wisely in healthcare: the first evidence from a systematic literature review. Int $\mathrm{J}$ Qual Health Care. 2017;29(7):889-895.

5. Grove AL, Meredith JO, Macintyre M, Angelis J, Neailey K. Lean implementation in primary care health visiting services in National Health Service UK. Qual Saf Health Care. 2010;19:e43.

6. Shortell SM, Blodgett JC, Rundall TG, Kralovec P. Use of lean and related transformational performance improvement systems in hospitals in the United States: results from a national survey. Jt Comm J Qual Patient Saf. 2018;in press.

7. Plsek P. Accelerating Health Care Transformation with Lean and Innovation: the Virginia Mason Experience. Boca Raton: CRC Press; 2014.

8. George ML, Rowlands D, Price M, Maxey J. The Lean Six Sigma Pocket Toolbook. New York: McGraw-Hill; 2005:36-54.

9. Burke RE, Kelley L, Gunzburger E, et al. Improving transitions of care for veterans transferred to tertiary VA medical centers. Am J Med Qual. 2018;33(2): 147-153.

10. Leonard C, Lawrence $\mathbf{E}$, McCreight $\mathbf{M}$, et al. Implementation and dissemination of a transition of care program for rural veterans: a controlled before and after study. Implement Sci. 2017;12(1):123.

11. May CR, Johnson M, Finch T. Implementation, context and complexity. Implement Sci. 2016;11(1):141.

12. Squires JE, Graham ID, Hutchinson AM, et al. Identifying the domains of context important to implementation science: a study protocol. Implement Sci. 2015;10:135.

13. Stange KC, Glasgow RE. Considering and Reporting Important Contextual Factors in Research on the Patient-Centered Medical Home. Rockville, MD: Agency for Healthcare Research and Quality; 2013. AHRQ publication 13-0045-EF.

14. Burke RE, Kripalani S, Vasilevskis EE, Schnipper JL. Moving beyond readmission penalties: creating an ideal process to improve transitional care. J Hosp Med. 2012;8(2):102-9.

15. Auerbach AD, Kripalani S, Vasilevskis EE, et al. Preventability and causes of readmissions in a national cohort of general medicine patients. JAMA Intern Med. 2016;176(4):484-493

16. Herzig SJ, Schnipper JL, Doctoroff L, Kim CS, Flanders SA, Robinson EJ, Ruhnke GW, Thomas L, Kripalani S, Lindenauer PK, Williams MV, Metlay JP, Auerbach AD. Physician perspectives on factors contributing to readmissions and potential prevention strategies: a multicenter survey. J Gen Intern Med. 2016;31:1287.

17. Burke RE, Lawrence E, Ladebue A, Ayele R, Lippmann B, Cumbler E, Allyn R, Jones J. How hospital clinicians select patients for skilled nursing facilities. J Am Geriatr Soc. 2017;65:2466-2472.

18. Burke RE, Jones J, Lawrence E, Ladebue A, Ayele R, Leonard C, Lippmann B, Matlock DD, Allyn R, Cumbler E. Evaluating the quality of patient decision-making regarding post-acute care. J Gen Intern Med. 2018;33:678.

19. Guest G, Bunce A, Johnson L. How many interviews are enough?: an experiment with data saturation and variability. Field Methods. 2006; 18(1):59-82.

20. Sandelowski M. Focus on qualitative methods: sample size in qualitative research. Res Nurs Health. 1995;18:179-183.

21. Visio: Work visually, Diagramming made simple. Available at: https:// products.office.com/en-us/visio/flowchart-software. Accessed 3 Dec 2018.

22. Sampalli T, Desy M, Dhir M, Edwards L, Dickson R, Blackmore G. Improving wait times to care for individuals with multimorbidities and complex conditions using value stream mapping. Int $\mathrm{J}$ Health Policy Manag. 2015;4(7):459-466.

23. Valsangkar NP, Eppstein AC, Lawson RA, Taylor AN. Effect of lean processes on surgical wait times and efficiency in a tertiary care veterans affairs medical center. JAMA Surg. 2017;152(1):42-47

Publisher's Note Springer Nature remains neutral with regard to jurisdictional claims in published maps and institutional affiliations. 